https://doi.org/10.48009/1_iis_2010_134-141

\title{
UNDERSTANDING THE BENEFITS OF SOCIAL EXCHANGE IN B2B COMMUNITIES
}

Lakisha L. Simmons, University of Mississippi, 1simmons@ olemiss.edu

Chris B. Simmons, University of Memphis, cbsmmons@memphis.edu

Anthony P. Ammeter, University of Mississippi, tammeter@bus.olemiss.edu

Kaushik Ghosh, Bloomsburg University of Pennsylvania, kghosh@bloomu.edu

\section{ABSTRACT}

The study focuses on why organizations host and why entrepreneurs participate in business-to-business (B2B) virtual communities. The answer to this question can aid hosting organizations in creating and using B2B virtual communities in ways that will provide them economic benefits. We use social exchange theory to develop a model and research hypothesis based on a synthesis of the $B 2 B e$ commerce and the virtual communities' literature. The empirical analysis of our model suggests that those who would participate in online discussions of a B2B virtual community develop trust in the host and trusting beliefs in the members of the community consistently. Host contributed information significantly impacts the members' decision to see the community as useful, and ultimately purchase products and services from the host. Member contributed feedback significantly impacts the perceived usefulness of the community as well as enhances the probability of economic success of the company hosting the community.

Keywords: B2B Virtual Communities, Virtual Community; Social Exchange Theory; Trust

\section{INTRODUCTION}

We investigate why organizations host and why entrepreneurs participate in business-to-business (B2B) virtual communities. While there has been recent research on the economic and cost benefits of hosting and participating in B2B e-commerce or emarketplaces [e.g., 5], there is scant research on the organizational benefits due to the social interaction or social networking that can occur in such B2B communities. There is a great deal of recent research on trust in doing business online [6], and the effects of social exchange and trust in virtual teams [29]. While many B2B e-marketplaces do not provide the types of forums necessary for such social interaction, it is our contention that those marketplaces that do provide these forums may yield benefits of a social or communal nature, and that these benefits may in turn result in extra economic benefits to the organization sponsoring the virtual community. This area is worthy of study because B2B e-commerce and emarketplaces are changing to promote more social interaction and benefits of doing so need to be explored.

Our research draws on social exchange theory (SET) to examine B2B virtual communities. This work makes two important contributions. First, it contributes to research by focusing on information sharing, relationship building, social interaction, and increased collaboration in B2B virtual communities, that is, communities organized by for profit organizations for use by other business organizations, whereas prior literature has focused on these aspects in customer-to-customer (C2C) communities or business-to-consumer (B2C) communities only. Second, it contributes to practice by investigating the benefits to sponsoring organizations and participants of organizing, facilitating, and participating in B2B virtual communities.

This paper is organized as follows. We first review the literature on socially-oriented virtual communities and follow this with a discussion of the relevant social phenomena in a B2B virtual community. Finally, we test our model based on a synthesis of the $\mathrm{B} 2 \mathrm{~B}$ e-commerce literature and the virtual communities' literature and conclude with suggested directions for future research.

\section{VIRTUAL COMMUNITIES}

While we are interested in the characteristics of a B2B virtual community, which we define as comprised of organizations participating in virtual communities, we lean on the most typical and most typically researched virtual communities which are member-to-member based relationships or customer to customer $(\mathrm{C} 2 \mathrm{C})$ relationships. $\mathrm{C} 2 \mathrm{C}$ communities promote communication between consumers in a computer-mediated environment [1]. Consumer goods companies build new relationships with their customers and consumers through online $\mathrm{C} 2 \mathrm{C}$ communities [17]. Many famous brands host online $\mathrm{C} 2 \mathrm{C}$ communities through mechanisms such as 
bulletin boards, forums, and chat rooms. Examples include CNN community, Disney family boards, the Shell International Petroleum forums, and Heineken [17].

\section{Value of Virtual Communities}

In recent years, with the increased popularity of networking virtual communities, more businesses are creating customer communities where customers can interact and share views on products with other consumers. Customers who participate in customer communities, such as the online auction website eBay, have been found to bid on products more often, win more auctions, and spend more money [2]. In essence, research shows us that customer communities lead to improved members' perceptions of the company and hopes of improved customer satisfaction [28].

Having high-participating users in a $\mathrm{C} 2 \mathrm{C}$ can lead to more personalized relationship feelings [15]. As customer relationships become more inherent in organization sponsored communities, firms having online B2C communities such as Bank of America can benefit. Firms that implement relationship marketing-based (RM-based) strategies recognize the importance of developing and maintaining long-term cooperative relationships with other firms [13]. There is a competitive advantage opportunity for both the business and the community sponsoring organization and therefore competitive outcomes for each. Relationship management is important in the company to customer relationship and, we argue, in the B2B relationship. When users feel such a connection with the online firm and other members, there is a reduction in consumer fears [15]. However, the interaction of trust and privacy concern in social networking sites is not yet understood to a sufficient degree to allow accurate modeling of behavior and activity [8]. Therefore, further research is necessary to understand the development of relationships, reasons for participation, and how such factors affect business owners.

\section{B2B Virtual Communities}

In spite of their relative scarcity in research on B2B virtual communities, there are some examples of companies that host $\mathrm{B} 2 \mathrm{~B}$ virtual communities, including Amazon.com and Bank of America (BoA). Amazon.com offers individuals the opportunity to create their own "aStore" featuring Amazon.com products. Within the Amazon online community, affiliates can participate in discussion boards and blogs. Amazon.com hosts the community and provides facilitators to monitor and participate in forums as necessary.

In 2007, BoA established a small business online community to empower people in building a successful business [4]. Members are not required to be a BoA small business customer to join the community. The BoA Small Business Online Community (BoASBOC) allows small businesses to exchange ideas, information, and benefit from the experience of others. The community provides forums to discuss topics with other members, a "success stories" section where business owners submit stories of how they overcame a business challenge, and member profile pages in which users can promote their business. BoA explicitly states its reason for hosting an online community as: "Our goal is to partner with small business owners across the country to help them achieve their dreams of owning and operating a successful business. We support this goal by offering a breadth of small businesses products and services to small businesses, as well as providing tools resources such as the Small Business Online Community" [4].

\section{Benefits of B2B Virtual Communities}

Prior research has encouraged B2B participation due to competitive advantage opportunities such as improved market share as a result of lower cost of gathering information from other businesses on the wants and needs of existing customers [5]. Research suggests that the main reasons for pursuing ebusiness partnerships are to reduce costs, cycle time, and eliminate paperwork and errors in the procurement process and in manual processes.

However, do businesses participating in a B2B virtual community result in increased economic benefits for the B2B virtual community sponsoring organization (e.g. BoA)? If so, what are the factors or variables that lead to purchases? This study focuses on why organizations host B2B virtual communities and the cost benefit impact on the hosting organization. Social networking communities create income from selling advertising space and we investigate the economic benefits and income potential for B2B sites that do not earn advertising income.

Social Exchange Theory explains the reason to participate in relationships often exhibited in virtual communities [11]. This theory suggests that human exchanges are formed and sustained by a subjective cost benefit approach. The more valuable the information received in the exchange, the greater the 
frequency of interaction and vice versa. If a behavior is not found rewarding, others in the exchange will reduce their production of a sentiment or activity of value [11]. Essentially, one will give if he or she believes he or she will receive just as much in return [8]. This might help explain why successful virtual communities are synonymous with highly active virtual communities.

\section{HYPOTHESIS DEVELOPMENT}

Building on SET and prior research, we have developed five hypotheses relating to the impact of social interaction on the economic benefits of participation in B2B virtual communities (Fig. 1).

Figure 1. Hypothesized Model

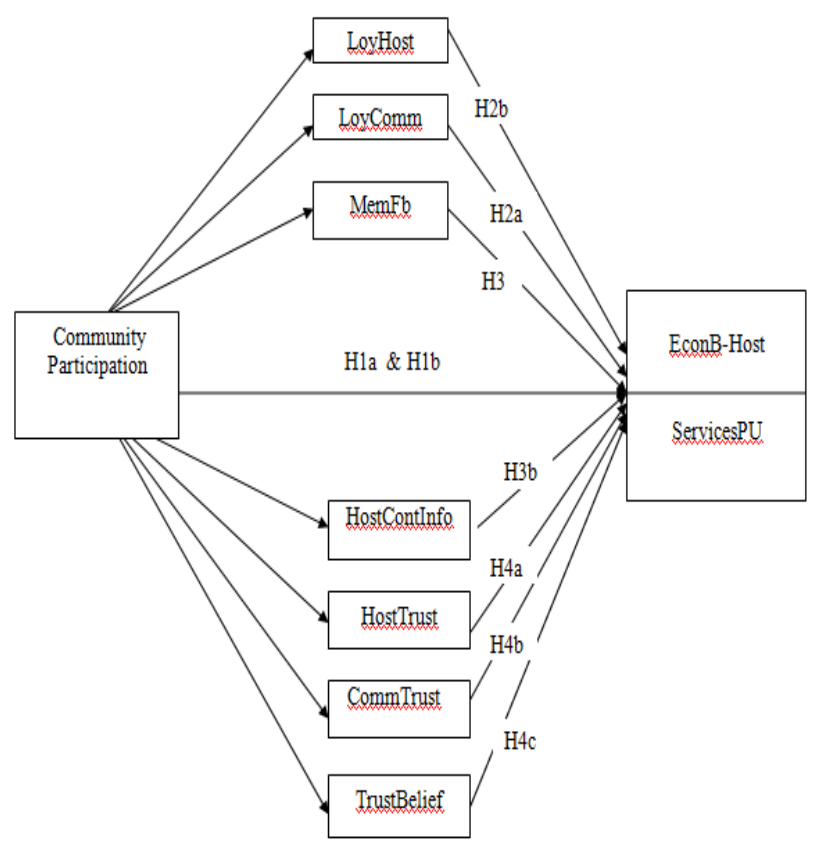

Key:

ServicesPU- Use of Services Perceived Usefulness

EconB-Host- Hosting Organization's Economic

Benefits

LoyComm- Loyalty to Community

LoyHost- Loyalty to Host Organization

CommParticipation- B2B Virtual Community

Participation

MemFb- Member Contributed Feedback

HostContInfo- Host Contributed Information

HostTrust- Host Trust

CommTrust- Community Trust

TrustBelief- Trust Belief
In B2B communities, every tool and aspect of the environment is geared towards the benefit of the business. Community participation does lead to sales in a C2C community as previously stated [1]. We propose that this will hold true in a B2B environment and that, all other things being equal, the more participation from a business, the more sales that will result for the $\mathrm{B} 2 \mathrm{~B}$ virtual community sponsoring organization. The potential to network and meet new clients is an incentive to participate in the community and support the organization sponsoring the community. We also propose that community participation is an indicator of the small business owner's perceived usefulness of the virtual community and potential to use the community network offline.

Hla: The higher the level of participation, the greater the economic benefit to the sponsoring organization in a $B 2 B$ virtual community.

H1b: The higher the level of participation, the greater the perceived usefulness of the $B 2 B$ virtual community.

In addition to the main-effect propositions stated above, social interaction in a B2B virtual community may also lead to benefits. We hypothesize that four factors -loyalty, education and training, knowledge, and trust - lead to outcomes that have economic benefit both for the organization sponsoring the virtual community and the businesses participating in the community. Loyalty has traditionally been described in two perspectives, behavioral, pure observable actions of loyal customers, and attitudinal, commitments to brands and repurchase intentions [23]. E-loyalty is an extension of the traditional context to describe the customer commitment to repurchase from the same brand or brand set $[9,22]$. Loyalty in B2B communities is developed when a business experiences behavior or attitudinal loyalty effects towards the hosting organization or another community member. Essentially, such business members choose to remain a loyal member because of feelings of belongingness and a benefit is realized. As in any relationship, this degree of loyalty takes time. But once community members feel such a connection rewards can be lifelong for the sponsoring organization.

We propose participation in a B2B virtual community will create e-loyalty, and thus create a sense of belongingness as members receive and contribute to the community. As members receive valuable first hand advice, a commitment to remain active in the community and give advice in return becomes self- 
obligatory, as discussed in social exchange theory. For example, a member feels "I received a benefit, I must return the benefit". Hence, we hypothesize that this obligatory feeling and loyalty to the community will lead to increased participation and thus not only attitudinal, but also behavioral loyalty and the member will become a lifetime purchasing member of the community. We propose the outcomes are worth the effort and costs of the community if in fact our hypothesis 2 holds true.

H2a: Participation in the B2B virtual community leads to $B 2 B$ community loyalty and ultimately greater economic benefit and perceived usefulness.

$H 2 b$ : Participation in the B2B virtual community leads to B2B community host loyalty and ultimately greater economic benefit and perceived usefulness.

B2B community members post discussions about the products and services offered by the hosting organization. Typical discussions may include feedback in the form of recommendations, opinions, and suggestions to solve business problems. Regardless of the medium or subject of feedback, word of mouth (WOM) has been recognized as the most effective communication channel and thus drives two-thirds of industries [14]. Consumer feedback has traditionally been in a WOM fashion but with substantial advances in electronic communication and increased use of the Internet, the term eWOM is now used to describe electronic WOM [12].

In the case of the BoASBOC, members can discuss products and services with other members before buying any product. Such a condition can impact a hosting organization because lurkers or first time visitors to the community can receive a lasting impression by a single comment about BoA from other members. This type of WOM can be substantial. For example, 81 percent of participants in an online survey said their perceptions are influenced to a positive extent by WOM in B2C environments [3]. Further studies are needed to determine eWOM impact in B2B environments. We propose that the increased product and service knowledge gained from feedback from other members, attainable only by being a member of the community, leads to purchases that may not have otherwise occurred.

P3a: Positive product and service feedback gained from other small business owners in B2B virtual communities leads to greater economic benefit and perceived usefulness.

Volume XI, No. 1, 2010
Education and training are important elements of business success through the development of human capital for increased productivity. A study of 405 North American firm executives in human capital by Molina and Ortega [19] showed high training and knowledge sharing firms not only benefit from higher employee satisfaction and lower turnover, but they are also able to translate these benefits into higher customer loyalty.

If $\mathrm{B} 2 \mathrm{~B}$ organizations can provide its business customers and future customers /community members with formal learning opportunities, they may be able to better retain their members based on social exchange theory. An investigation conducted by Simpson, Tuck, and Bellamy [24] showed clear evidence that education and training had a positive effect on the success of small businesses, which are often members of B2B communities. If business partners who participate in B2B communities can take advantage of host organization product and service education and training opportunities, they may be more willing to purchase such products and services from the community hosting organization.

The Internet architecture of virtual communities can enable many types of education and training opportunities in B2B virtual community settings. Online end user training is one of the methods used in virtual communities to provide various training opportunities for B2B members. Message boards, articles, and direct links to training documents are other methods for providing member access to educational and training materials. As businesses take advantage of information exchange, learning opportunities, and training opportunities with other members, they receive a benefit that may lead to more informed purchasing activity among members.

H3b: Greater information exchange, education, and training opportunities available to $B 2 B$ virtual community members from the $B 2 B$ virtual community host leads to a greater economic benefit and perceived usefulness.

As long as retailers are participating and engaging in a community interact with other members, a subconscious sense of trust is being built in the individuals. Members will become more dependent on the other members and value their opinions and advice more as time increases. The more trust that a member feels in the community, the more purchasing activity can be expected.

H4a: The B2B virtual community host gains trust from small business owners participating in a $B 2 B$ 
virtual community and the trust leads to an economic benefit and perceived usefulness.

$H 4 b$ : The B2B virtual community members gain trust from other small business owners participating in a $B 2 B$ virtual community and the trust leads to an economic benefit and perceived usefulness.

$H 4 c$ : The B2B virtual community has trusting beliefs from small business owners participating in a B2B virtual community and the trust leads to an economic benefit and perceived usefulness.

\section{RESEARCH METHOD}

The current study's primary purpose is to verify the suitability of the model to analyze the theory and to improve the quality of the survey instrument to be used later with the business owners. Hence, we used role playing as a technique to learn more about the psychological processes of users of $\mathrm{B} 2 \mathrm{~B}$ virtual communities. Role playing studies are conducted to learn about attitudes and behaviors in a psychological context, learn what people think they would do in a situation [10]. Even though what people say they will do is not always what actually happens, there is value in knowing what people think they would do.

An online questionnaire with a pretext scenario was made available to students in a College of Business of a doctoral granting university in the southern part of the United States. Subjects were given descriptions to read about the community including discussions among members and information on upcoming training opportunities. They were asked to put themselves in the place of a small business owner considering participating in the community. The survey instrument which contained pre-existing scales was administered to five different classes within a two day period, which provided 275 complete responses.

Pre-existing scales were used to measure the constructs in the hypothesized model were modified to fit the context of our study [7, 16, 18, 20, 27, 30]. These scales were based on a 7-point Likert scale varying from "strongly disagree" (1) to "strongly agree" (7). Computer self-efficacy was used as a control variable.

\section{DATA ANALYSIS \& RESULTS}

Regression analysis was used to test our model. We used Sobel.spss.sbs script [21] to test for mediation in
SPSS 17.0. Table 1 shows a summary of the results that were found when computer self-efficacy was used as a control and regression was used to analyze the model. Cronbach's alpha reliabilities of each scale are all above .83 .

Table 1. Regression Results Summary

\begin{tabular}{|c|c|c|}
\hline Hypothesis & Relationship & Result \\
\hline H1a & $\begin{array}{l}\text { CommPart } \\
\text { EconB-Host }\end{array} \longrightarrow$ & $\begin{array}{l}\text { Supported } \\
\left(0.15^{*}\right)\end{array}$ \\
\hline H1b & $\begin{array}{l}\text { CommPart } \\
\text { ServicesPU }\end{array} \longrightarrow$ & $\begin{array}{l}\text { Supported } \\
\left(0.12^{*}\right)\end{array}$ \\
\hline $\mathrm{H} 2 \mathrm{a}$ & $\begin{array}{l}\text { LoyComm } \\
\text { EconB-Host } \\
\text { ServicesPU }\end{array}$ & Not Supported \\
\hline $\mathrm{H} 2 \mathrm{~b}$ & $\begin{array}{l}\text { LoyHost } \\
\text { EconB-Host } \\
\text { ServicesPU }\end{array}$ & $\begin{array}{l}\text { Partially } \\
\text { Supported } \\
\left(0.11^{*}\right)\end{array}$ \\
\hline $\mathrm{H} 3 \mathrm{a}$ & 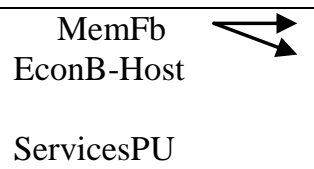 & Not Supported \\
\hline $\mathrm{H} 3 \mathrm{~b}$ & $\begin{array}{l}\text { HostContInfo } \longrightarrow \\
\text { EconB-Host } \\
\text { ServicesPU }\end{array}$ & Not Supported \\
\hline $\mathrm{H} 4 \mathrm{a}$ & 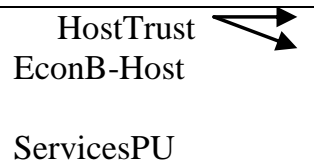 & $\begin{array}{l}\text { Supported } \\
(0.17 *) \\
\left(0.18^{*}\right)\end{array}$ \\
\hline $\mathrm{H} 4 \mathrm{~b}$ & $\begin{array}{l}\text { CommT } \\
\text { EconB-Host } \\
\text { ServicesPU }\end{array}$ & $\begin{array}{l}\text { Supported } \\
(0.12 *) \\
(0.12 *)\end{array}$ \\
\hline $\mathrm{H} 4 \mathrm{c}$ & $\begin{array}{l}\underset{\text { TrustBelief }}{\text { EconB-Host }} \\
\text { ServicesPU }\end{array}$ & $\begin{array}{l}\text { Supported } \\
\left(0.09^{*}\right) \\
\left(0.10^{*}\right)\end{array}$ \\
\hline
\end{tabular}

\section{Direct Effects}

Community participation had a significant positive effect on the economic benefits (H1a, $\beta=0.15$ ) to the organization hosting the virtual community, thus implying that member participation in a $\mathrm{B} 2 \mathrm{~B}$ virtual community is critical to the commercial success of the hosting organization. Community participation also had a significant impact on the perceived usefulness of the B2B virtual community (H1b, $\beta=$ 0.12 ). This suggests that an individual's participation 
in the virtual community determined his or her perceptions of the usefulness of the community.

\section{Mediated Effects}

Loyalty to the community did not mediate the relationship between community participation and economic benefits to hosting organization nor did it mediate the relationship between community participation and perceived usefulness of the B2B community. Hence, there was no support for H2a. However, community participation was positively related to loyalty towards community $(\beta=0.61)$. In addition, loyalty to community impacted economic benefits positively $(\beta=0.39)$ as well as perceived usefulness of the B2B community $(\beta=0.28)$.

Loyalty to the host did not mediate the relationship between community participation and economic benefits to the hosting organization. However, loyalty to host mediated the relationship between community participation and perceived usefulness of the B2B community $(\beta=0.11)$. Hence, there was partial support for $\mathrm{H} 2 \mathrm{~b}$. Moreover, there was significant positive effects of community participation on loyalty to host $(\beta=0.56)$ as well as loyalty to host on economic benefits $(\beta=0.39)$.

Member feedback did not mediate the relationship between community participation and economic benefits to hosting organization. Also, member feedback did not mediate the relationship between community participation and perceived usefulness of the B2B community. Thus, H3a was not supported. But member feedback impacted economic benefits to the host organization $(\beta=0.49)$ and community participation impacted member feedback $(\beta=0.44)$. Further, there was significant positive relationship between member feedback and perceived usefulness of the B2B community $(\beta=0.39)$.

Host contributed information did not mediate the relationship between community participation and economic benefits to host organization as well as it did not mediate the relationship between community participation and perceived usefulness of the B2B community. Hence, $\mathrm{H} 3 \mathrm{~b}$ was not supported. Community participation had a significant positive effect on host contributed information $(\beta=0.28)$ and host contributed information had a significant positive effect on economic benefits $(\beta=0.65)$. Additionally, host contributed information was positively and significantly related to perceived usefulness $(\beta=0.71)$.

Host trust mediated the relationship between community participation and economic benefits to

Volume XI, No. 1, 2010 the host organization $(\beta=0.17)$. Also, it mediated the relationship between community participation and perceived usefulness of the host organization $(\beta=$ 0.18). Consequently, $\mathrm{H} 4 \mathrm{a}$ was supported. Furthermore, community participation had a positive effect on host trust $(\beta=0.17)$, and host trust was positively related to economic benefits to host organization $(\beta=0.47)$ and to perceived usefulness $(\beta=0.45)$.

Community trust mediated the relationship between community participation and economic benefits to the host organization $(\beta=0.12)$. Further, it mediated the relationship between community participation and perceived usefulness $(\beta=0.12)$. Therefore, $4 \mathrm{~b}$ was supported. Also, community participation had a significant positive effect on community trust $(\beta=$ 0.22 ). Community trust was related to economic benefits $(\beta=0.6)$ and to perceived usefulness $(\beta=$ $0.59)$.

Trusting beliefs mediated the relationship between community participation and economic benefits to the host organization $(\beta=0.09)$. Trusting beliefs also mediated the relationship between community participation and perceived usefulness $(\beta=0.10)$. Thus, $\mathrm{H} 4 \mathrm{c}$ was supported. Trusting beliefs positively impacted economic benefits $(\beta=0.71)$ and community participation had a significant positive effect on trusting beliefs $(\beta=0.22)$. In addition, trusting beliefs was positively associated with perceived usefulness $(\beta=0.67)$.

\section{LIMITATIONS}

Using current business owners as the main respondent of the survey could yield greater validity of the results. The current study results can be used to verify the suitability of the model to analyze the theory and to improve the quality of the survey instrument to be used later with the real business owners. While we see the relative small population of B2B virtual communities as a potential limitation to doing this kind of research, we believe that such research is still important and is worthy of pursuit. A follow up study would be to incorporate the above into a case study of two different types of B2B virtual communities. In the case of BoA and Amazon.com, comparing the two would allow a comparison of a customer-required community (i.e. to become a member one must be a customer first) with a noncustomer required community of small business owners.

\section{CONCLUSION}

Issues in Information Systems 
Prior research has been conducted on what makes a C2C community successful [25]. Yet little is known about the impact of participation in B2B virtual communities consisting of small businesses on economic benefits to the members. The US office of advocacy states that $97.5 \%$ of the 26 million firms in the US are firms with less than 20 employees but account for half of the non-farm GDP [26] and therefore are important to study. Our model suggests that community participation is a strong predictor of economic benefits to hosts of B2B virtual communities. In addition, factors such as loyalty to the community and to the host predicted economic benefits to the host organization, Member feedback was positively related to both economic benefits, as well as perceived usefulness of the community, advocating that feedback from individuals in the community ascertained to a certain degree, the economic benefit potential of the organization hosting the B2B virtual community. Further, organizations hosting the virtual community should provide valuable, relevant, and timely information to members. In addition, trust in the organization hosting the community, trust among members, and trusting beliefs predicted the success of host organization. This leads us to believe that trust plays a central role in promoting $\mathrm{B} 2 \mathrm{~B}$ virtual communities.

Our findings have implications for theory and practice. Significance of the role of community participation, perceptions of individual loyalty, the role of feedback, trust, and content of relevant information in predicting the commercial success of organizations is useful advice for organizations hosting B2B communities. Overall, we believe that the information derived from our research will aid managers of companies in creating and using B2B virtual communities in ways that will provide the greatest economic benefit.

\section{REFERENCES}

1. Adjei, M. T. (2006). Online Customer-toCustomer Communications as Drivers of Relationship Quality and Purchase Behavior, doctoral dissertation, The University of Mississippi.

2. Algesheimer, R. and Dholakia, P. (2006). Do customer communities pay off? Harvard Business Review, 84 (11), 26-30.

3. Allsop, D., Bassett, B., and Hoskins, J. (2007). Word-of-Mouth Research: Principles and

Volume XI, No. 1, 2010 applications, Journal of Advertising Research, 47 (4), 398-411.

4. Bank of America. Small business online community. Retrieved February 15, 2009 from http://smallbusinessonlinecommunity.bankofame rica.com/index.jspa

5. Barnes-Vieyra, P., and Claycomb, C. (2001). Business to business e-commerce: Models and managerial decisions, Business Horizons, 44 (3), 13-20.

6. Chen, Y.-H., \& Barnes, S. (2007). Initial trust and online buyer behavior. Industrial Management and Data Systems, 107, 21-36.

7. Davis, F. (1989). Perceived usefulness, Perceived Ease of Use, and User Acceptance of Information Technology, MIS Quarterly, 13 (3), 319-340.

8. Dwyer, C., Hiltz, S., and Passerini, K., (2007). Trust and privacy concern within social networking sites: A comparison of Facebook and MySpace. Proceedings of the Thirteenth Americas Conference on Information Systems, Keystone, Colorado August 09 - 122007.

9. Gommans M, Krishman K, and Scheffold K. (2001). From Brand Loyalty to E-Loyalty: A Conceptual Framework, Journal of Economic \& Social Research, 3 (1), 43-50.

10. Greenberg, J. and Eskew, D. E. (1993). The role of role playing in organizational research, Journal of Management, 19 (2), 221-241.

11. Homans, G. C. (1958). Social Behavior as Exchange. American Journal of Sociology, 63, (6) 597-606.

12. Hung, K., and Yiyan Li, S. (2007). The Influence of eWOM on Virtual Consumer Communities: Social Capital, Consumer Learning, and Behavioral Outcomes, Journal of Advertising Research, 47 (4), 485-495.

13. Hunt, S., Arnett, D. and Madhavaram, S. (2006). The explanatory foundations of relationship marketing theory, The Journal of Business \& Industrial Marketing: Relationship Theory and Business Markets, 212: 72.

14. Keller, E. (2007). Unleashing the Power of Word of Mouth: Creating Brand Advocacy to Drive 
Growth, Journal of Advertising Research, 47 (4), 448-452.

15. Klang, M. (2001). Who do you trust? Beyond encryption, secure e-business, Decision Support Systems, Special issue: Electronic commerce. 31 (3), 293-301.

16. Lin, T., and Huang, C. (2008). Understanding knowledge management system usage antecedents: An integration of social cognitive theory and task technology fit, Information \& Management, 45 (6), 410-417.

17. McWilliam, G. (2000). Building stronger brands through online communities, MIT Sloan Management Review, 413, 43-54.

18. Mollenkopf, D., Rabinovich, E., Laseter, T., and Boyer, K. (2007). Managing Internet Product Returns: A Focus on Effective Service Operations, Decision Sciences, 38 (2), 215-250.

19. Molina, J., and Ortega, R. (2003). Effects of employee training on the performance of NorthAmerican firms. Applied Economics Letters, 10 (9), 549-560

20. Pavlou, P., and Gefen, D. (2004). Building Effective Online Marketplaces with InstitutionBased Trust. Information Systems Research, 15 (1), 37-59.

21. Preacher, K. J., \& Hayes, A. F. (2008). Asymptotic and resampling strategies for assessing and comparing indirect effects in multiple mediator models. Behavior Research Methods, 40, 879-891. Macro downloaded from http://www.comm.ohio-

state.edu/ahayes/SPSS\%20programs/indirect.htm on March 10, 2009.

22. Reichheld, F. and Schefter, P. (2000). E-Loyalty, Harvard Business Review, 78, (4) 105-113.

23. Russell-Bennett, R., McColl-Kennedy, J., and Coote, L. (2007). Involvement, satisfaction, and brand loyalty in a small business services setting, Journal of Business Research, 60 (12), 12531260.

24. Simpson, M., Tuck, N., and Bellamy, S. (2004). Small business success factors: the role of education and training, Education \& Training, 468 , (9) 481-491.

25. Tarmizi, H., Vreede, G., and Zigurs, I., (2007). A Facilitators' Perspective on Successful Virtual Communities of Practice. Proceedings of the Thirteenth Americas Conference on Information Systems, Keystone, Colorado August 09 - 12 2007.

26. United States Small Business Administration Office of Advocacy. (2006). The small business economy: a report to the president 2006. Retrieved November 15, 2007 from: http://www.sba.gov/advo/research/sb_econ2006. pdf.

27. Wiertz, C., and de Ruyter, K. (2007). Beyond the Call of Duty: Why Customers Contribute to Firm-hosted Commercial Online Communities, Organization Studies, 28 (3), 347-376.

28. Williams, R. and Cothrel, J. (2000). Four smart ways to run online communities. MIT Sloan Management Review, 41 (4), 81-91.

29. Workman, M. (2008). The effects from technology-mediated interaction and openness in virtual team performance measures. Journal of Behaviour \& Information Technology, 26, 355365.

30. Wu, Jyh-Jeng, and Tsang, Alex S. L. (2008). Factors affecting members' trust belief and behaviour intention in virtual communities, Behavior \& Information Technology, 27 (2), 115-125. 